\title{
ACESSO NAS POLÍTICAS DA EDUCAÇÃO SUPERIOR: DIMENSÕES E INDICADORES EM QUESTÃO
}

\author{
Maria das Graças Martins da Silva* \\ Tereza Christina Mertens Aguiar Veloso**
}

Recebido: 29 mar. $2012 \quad$ Aprovado: 19 abr. 2012

\begin{abstract}
*Programa de Pós-graduação em Educação da Universidade Federal de Mato Grosso. Cuiabá, MT, Brasil. Contato com a autora: gracams2@hotmail.com

**Programa de Pós-graduação em Educação da Universidade Federal de Mato Grosso. Cuiabá, MT, Brasil. Contato com a autora: tecmav@terra.com.br
\end{abstract}

Resumo: $\mathrm{O}$ texto tem por objetivo abordar o acesso à educação superior na perspectiva de atribuir-lhe uma significação e propor indicadores para balizá-lo, tendo em vista a democratização do acesso e/ ou o pleno acesso. A par disso, traça um panorama das políticas da educação superior e apresenta um quadro da realidade, com base na pesquisa bibliográfica e documental. Conclui que os avanços observados transcorrem sem referência ao acesso democrático, no que esse tem de elevado, substancial, abrangente.

Palavras-chave: Acesso à educação superior. Democratização do acesso. Acesso democrático.

\author{
ACCESS IN HIGHER EDUCATION POLICIES: \\ DIMENSIONS AND INDICATORS UNDER CONSIDERATION
}

Abstract: The objective of the text is to approach the topic access to higher education in the perspective of giving it a meaning and proposing indicators to delimit it, aiming at the democratization of access and/or total access. With this in mind, the paper traces an overview of the policies of higher education and presents a picture of the reality, based on bibliographic and documental research. The conclusions show that the progress observed does not derive from any reference to democratic access and to what it has of elevated, substantial, and inclusive.

Key words: Access to higher education. Democratization of access. Democratic access.

\section{INTRODUÇÃO}

O termo "acesso" à educação superior se manifesta fluentemente nos documentos que tratam da regulação das políticas educacionais e nos que as analisam, conforme se mostra no presente texto. Contudo, estudos indicam que o seu entendimento propriamente é pouco enfocado ou apresenta-se evasivo (SILVA, VELOSO, 2010). O acesso, a princípio, encerra consensos; todavia, ao riscar o verniz do discurso, emergem questões perturbadoras: quem acessa?; qual é o tamanho do acesso?; que tipo de acesso?; acessar promove que outros acessos? 
O texto em tela pretende abordar o acesso à educação superior ${ }^{1}$ na perspectiva de atribuir-lhe uma significação, e, indo mais além, propor indicadores com vista a balizá-lo, procurando levar em conta a realidade complexa em que se situa o problema. A par disso, traça um panorama de certas políticas da educação superior, tomando por base o sentido democrático e/ou democratizante do acesso. Nesse empreendimento, apóia-se na pesquisa bibliográfica para tratar de conceitos e na pesquisa documental para consulta a legislação, propostas educacionais e indicadores da educação superior.

De acordo com a estrutura do texto, inicialmente, analisa-se o acesso na dimensão categorial, e, num segundo momento, democracia e democratização, considerando a sua recorrente associação na pauta do acesso. Na sequência, evidencia-se o acesso posto na realidade, a partir de suas dimensões e de seus indicadores. Por fim, conclui-se que a democratização do acesso realiza-se como um processo incompleto e distante do acesso democrático propriamente, no que esse tem de elevado, substancial, abrangente.

\section{A CATEGORIA ACESSO EM DISCUSSÃO}

Segundo Campos (1988), categoria é uma palavra de origem grega que significa atributo. Complementarmente, para Triviños (2004) categoria é um produto da atividade cognitiva, que pretende explicar, pelo pensamento abstrato, a realidade concreta. Seguindo essa linha, Cheptulin (2004) considera que as categorias são produzidas no campo da consciência e correspondem às propriedades e conexões universais do que está na realidade; portanto, dela partindo e nela se fundamentando ${ }^{2}$.

No sistema categorial de Minayo (2000, p. 94), as categorias analíticas “[...] retêm historicamente as relações sociais fundamentais e podem ser consideradas balizas para o conhecimento do objeto nos seus aspectos gerais. Elas mesmas comportam vários graus de abstração, generalização e de aproximação."

1 O estudo faz parte das atividades da pesquisa interinstitucional "Acesso e permanência no processo de expansão da educação superior no Brasil pós-LDB", financiada pelo CNPq, da qual participam as autoras. Essa, por sua vez, integra a pesquisa "Políticas de expansão da educação superior no Brasil pós-LDB", que envolve pesquisadores de quatro regiões do país, vinculados à Rede Universitas BR.

2 Para Cheputlin (2004) a natureza das categorias tem a ver com a correlação entre o particular e o geral. $\mathrm{O}$ singular representa as propriedades e ligações próprias de determinada formação material, portanto, $\mathrm{o}$ que não existe em outras. Já o geral corresponde ao que se repete nas formações materiais, ao que não é próprio apenas de uma formação. No entanto: "Cada formação material, cada coisa representa a unidade do singular e do geral, do que não se repete e do que se repete." (p. 195). Na medida em que um objeto abrange o singular e o geral, ao mesmo tempo, passa a se chamar particular. Assim: "A correlação do particular e do geral representa uma correlação do todo e da parte [...].” (p. 196). 
Já as categorias empíricas são "[...] construídas com finalidade operacional, visando ao trabalho de campo (a fase empírica) ou a partir do trabalho de campo". A autora pondera que, em certos casos, a categoria empírica pode relacionar-se intrinsecamente com a categoria analítica; isto é, pode "[...] ser colocada no quadro mais amplo de compreensão teórica da realidade e, ao mesmo tempo, expressá-la na sua especificidade".

Nesse caso, a categoria empírica se entrelaça à analítica (e vice-versa), permitindo enriquecer o quadro reflexivo. Ao se considerar a distinção e, ato imediato, a imbricação entre o analítico e o empírico (operação que busca aprofundar o conhecimento da realidade), não se pretende sugerir que seja possível uma categoria constituir-se independente do real. Ao contrário, como já mencionado, as categorias refletem o real, criam-se pelo seu registro na consciência. Assim, as distinções e as articulações em vista têm por finalidade organizar a apreensão da realidade no plano do pensamento.

Tem-se, então, que a categoria analítica reporta-se às propriedades gerais e universais dos fenômenos materiais; por sua vez, a empírica relaciona-se ao campo de estudo específico do pesquisador. Entende-se que o acesso pode ser considerado uma categoria analítico-empírica por abarcar, simultaneamente, a dimensão do geral e do singular.

Segue-se que, numa definição preliminar e abrangente, acesso significa "fazer parte"; por conseguinte, remete à inserção, participação, acolhimento. Entretanto, o acesso pode ser entendido mais profundamente, de forma a transcender a contradição que emerge dessa compreensão, que se relaciona à dualidade "incluído/excluído", "integrado/não integrado", "parte/todo". Acesso, num sentido mais profundo, refere-se a um pertencimento que se liga indissociavelmente ao senso de coletividade/universalidade e à práxis criativa. Quer dizer, agrega-se ao sentido de igualdade e de liberdade. Tal entendimento inspira-se em Marx (2005), para quem: "A minha própria existência é atividade social. Por conseguinte, o que eu próprio produzo é para a sociedade que o produzo e com a consciência de agir como ser social". A inspiração vem, igualmente, de Kosik (2002), em que a práxis se constitui na unidade do indivíduo com o mundo, na sua objetivação no mundo para a realização da liberdade humana.

Sob tais referencias, indaga-se: é possível estabelecer parâmetros para avaliar o acesso na realidade? É o que se tenta construir no que segue.

$\mathrm{Na}$ perspectiva da educação superior, de início e objetivamente, acesso implica no ingresso a esse nível de ensino, quer dizer, no ato de passagem para o espaço acadêmico. No entanto, é limitante ver nisso um desfecho, visto que 
pesquisas sobre evasão têm mostrado que o ingresso não assegura a efetiva continuidade ou a conclusão do trajeto acadêmico (VELOSO, 2000; SILVA FILHO et al, 2007). Assim, é necessário considerar a dimensão de permanência, que sinaliza o percurso seqüente e bem sucedido. Por fim, há de abarcar a qualidade da formação, que talvez mereça uma argumentação mais detida devido a que se tornou lugar-comum o seu uso em discursos ou documentos oficiais que tratam das políticas educacionais, concorrendo para banalizar o seu sentido. Enguita (1996, p. 95) expressa que qualidade é a palavra em moda no mundo da educação, localizada desde "[...] as declarações dos organismos internacionais até conversas de bar, passando pelas manifestações das autoridades educacionais [...]", todos, enfim, coincidindo em aceitá-la como objetivo prioritário da educação ou do ensino. Mesmo levando em conta o viés ideológico presente - o que requer uma depuração - considera-se necessário ligar ao acesso uma dimensão que abrigue noções de objetivos educacionais. Acolhe-se o termo "formação qualificada", pretendendo remeter a bases materiais e subjetivas que favoreçam à apropriação do conhecimento crítico e à formação de sujeitos-protagonistas no processo educacional. Ou que expresse o conhecimento como um modo de apropriação do mundo, de compreensão e re-criação da realidade, como indica Kosik (2002).

Assim, adotar o ingresso, a permanência e a qualidade na formação, alarga e aprofunda a definição do acesso, contrapondo-se a uma visão fragmentada e imediatista.

O passo seguinte refere-se a construir indicadores para cada uma das dimensões, os quais tenham potencial de aferição na realidade. Assim, para analisar o acesso na sua etapa inicial (o ingresso), propõe-se a observação da oferta de vagas, do ingresso propriamente e da forma de seleção. Como indicadores da permanência, dados relativos à matrícula, à taxa de diplomação e a programas de fixação do estudante na academia. E para a qualidade na formação é possível ter em vista: categoria administrativa; organização acadêmica; titulação e dedicação do corpo docente; participação discente/docente nas decisões; escolha do curso; avaliação institucional; produção da pesquisa; autonomia político-pedagógica e financeira.

Importante registrar que os indicadores sugeridos podem ser ampliados ou alterados ao submeterem-se a específicas realidades e enfoques investigativos. Exemplo disso, embora aqui não considerado, refere-se ao indicador interiorização, imprescindível para o exame de certas realidades no país.

Considerando as dimensões e os indicadores assinalados, a categoria analítico-empírica do acesso pode ser traduzida pelo seguinte esquema: 


\begin{tabular}{|c|c|c|c|}
\hline \multirow[t]{2}{*}{$\begin{array}{c}\text { Categoria } \\
\downarrow\end{array}$} & $\begin{array}{c}\text { Dimensões } \\
I\end{array}$ & & $\begin{array}{c}\text { Indicadores } \\
I\end{array}$ \\
\hline & Ingresso & $\mapsto$ & Vagas, ingresso, formato seletivo \\
\hline \multirow[t]{2}{*}{ Acesso } & Permanência & $\mapsto$ & $\begin{array}{l}\text { Matrícula, taxa de diplomação, } \\
\text { programas de fixação do estudante. }\end{array}$ \\
\hline & Qualidade da formação & $\mapsto$ & $\begin{array}{l}\text { Categoria administrativa; organização } \\
\text { acadêmica; da formação titulação } \\
\text { e dedicação do corpo docente; } \\
\text { participação discente/docente nas } \\
\text { decisões; escolha do curso; avaliação } \\
\text { institucional; produção da pesquisa; } \\
\text { autonomia política pedagógica e } \\
\text { financeira. }\end{array}$ \\
\hline
\end{tabular}

Tecendo esses fios, se pode ir adiante. Ao examinar as dimensões que comporta, tomando-as no conjunto, segundo indicadores quantitativos (quantos?) e qualitativos (a quem? a que fins? como?), provavelmente, se possa apreender as possibilidades da democratização do acesso e do acesso democrático. Entende-se, pois, que democratizante ou democrático referem-se a atributos do acesso, capazes de explicitar as suas características em face da realidade e avaliar o seu quilate.

\section{ACESSO DEMOCRÁTICO, DEMOCRATIZAÇÃO DO ACESSO}

Considera-se que "acesso democrático" seria uma redundância, em condições plenas de acesso. Entretanto, em face da realidade contraditória, o atributo "democrático" é um reconhecimento de que o acesso precisa ser situado, avaliado. E, porque não é pleno, precisa "democratizar-se". A par disso, insurge a questão que provoca o texto: acesso democrático e democratização do acesso têm quais sentidos e como se manifestam na realidade, tendo em vista as políticas da educação superior?

Fazendo-se uma digressão histórica, conforme Bobbio (2004), os princípios da democracia polarizam-se de acordo com o liberalismo democrático e o socialismo democrático. No primeiro, liga-se à forma de governar, ao exercício político representativo, ao modo de transmissão do poder, enfim, ao sistema formal de participação. Nesse âmbito, do ponto de vista do direito, envolve sufrágio universal e livre, bem como liberdades civis (ELEY, 2002).

Já no escopo do socialismo, a democracia envolve e transcende o exercício político em si, articulando-o à emancipação econômica, ou melhor, a "uma forma 
geral de existência social", que, no entendimento de Silva (2006, p. 12), significa o "usufruto coletivo dos bens materiais, culturais, artísticos e educacionais produzidos pela humanidade". Por isso, conclui-se que a sua efetivação, sob o capitalismo, é uma quimera, podendo se realizar apenas parcialmente, tendo em vista a divisão em classes ou a desigualdade social que pauta a sociedade. Desse conjunto, se conclui que na democracia socialista o poder político não está isolado das condições concretas de existência, de modo que as noções de igualdade e de liberdade completam-se e influenciam-se.

Por consequência, segundo Coutinho (2002, p. 17): "a plena realização da democracia implica a superação da ordem social capitalista." Para o autor, entretanto, a democracia não deve ser meramente cultuada ou tida como irrealizável, e, sim, anunciadora de valores e utopias viabilizáveis. Então, dado que se vive objetivamente sob as condições da sociedade capitalista, tem-se o complexo desafio de forjar a democracia em meio às contradições do sistema. Dir-se-ia, pois, que se trata de uma democracia contraditória, visto que, em razão da lógica e dinâmica do sistema, os eventuais avanços na distribuição dos bens sociais serão sempre restringidos para quem não detém o capital.

Abrem-se, pois, possibilidades próprias de compreensão para os termos em pauta, embora sem perder de vista a unidade e as influências mútuas. A par disso, entende-se que democratização refere-se aos avanços sociais, que podem engendrar mudanças na direção da democracia (em sentido pleno). Em determinadas condições e motivações, a democratização pode constituir-se em elemento fundamental à construção da democracia, a exemplo de certas iniciativas no campo da educação. Nessa linha, a "democratização referenciada na democracia" reporta e se condiciona ao enfrentamento de elementos causais e projeta embates que põem em questão estruturas enraizadas, ou, no limite, a própria ordem social vigente.

Cabe reforçar que democracia e democratização completam-se, de modo que submeter a um desmembramento é exercício de apurar a compreensão do real. Nessa via, como já explicado, a democracia presume um desenvolvimento, um curso - aqui tratado como democratização. Todavia, para evitar dualismos inconseqüentes, recorre-se a Wood (2003), para quem o surgimento das relações capitalistas de propriedade consumou a democracia sob determinados padrões e ideário. A seu ver: "O capitalismo tornou possível a redefinição de democracia e sua redução ao liberalismo" (p. 201, grifo da autora). Daí concluir que, essa democracia identifica-se com seus traços fundantes (mercado, exploração do trabalho, propriedade, classes, etc.). Assim, há de levar em conta a apropriação ideológica que o sistema realiza, processando uma assepsia do sentido trans- 
formador das coisas e as condicionando ao reino do mercado. Seguindo Wood (2003), tem-se clareza de que os efeitos da democracia sob o capitalismo produzem ambigüidades que podem levar à ilusão da "transição suave da democracia capitalista para a socialista" ou "a realização das aspirações democráticas nos interstícios do capitalismo". Por isso:

É necessário, em primeiro lugar, não ter ilusões acerca do significado e dos efeitos da democracia no capitalismo. Isso representa não somente a compreensão dos limites da democracia capitalista, o fato de que até mesmo um Estado capitalista democrático pode ser restringido pelas exigências de acumulação do capital, e o fato de que a democracia liberal deixa essencialmente intacta a exploração capitalista [...]. (WOOD, 2003, p. 233, grifos da autora).

Em outras palavras, a democratização não necessariamente pode evoluir para a democracia (pelo contrário, sob o capitalismo, a democracia tende a embotar); no entanto, a democracia se constrói levando em conta o compasso da democratização.

Tais referências passam a nortear a avaliação que se faz do acesso, tendo em vista a sua configuração nas políticas públicas.

\section{ACESSO NAS POLÍTICAS DA EDUCAÇÃO SUPERIOR}

Um movimento inicial e necessário para compreender o acesso à educação superior no plano da realidade remete à legislação, bem como aos planos e programas vigentes, os quais traduzem as políticas encaminhadas pelo poder público.

Tomando as leis de referência maior, a Constituição Federal (CF) e a Lei de Diretrizes e Bases (LDB), o que segue resume pontos relacionados direta ou indiretamente ao acesso.

Na Constituição Federal de 1988 são destacados:

\begin{tabular}{|l|l|}
\hline $\begin{array}{l}\text { artigo } \\
206\end{array}$ & $\begin{array}{l}\text { O ensino será ministrado com base no principio igualdade de condições para acesso } \\
\text { e permanência (I) e de gratuidade do ensino público em estabelecimentos oficiais (IV) }\end{array}$ \\
\hline $\begin{array}{l}\text { artigo } \\
207\end{array}$ & $\begin{array}{l}\text { As universidades gozam de autonomia didático-científica, administrativa e de gestão } \\
\text { financeira e patrimonial, e obedecerão ao princípio de indissociabilidade entre ensino, } \\
\text { pesquisa e extensão }\end{array}$ \\
\hline $\begin{array}{l}\text { artigo } \\
208\end{array}$ & $\begin{array}{l}\text { O dever do estado com a educação será efetivado mediante a garantia de acesso } \\
\text { aos níveis mais elevados do ensino, da pesquisa e da criação artística, segundo a } \\
\text { capacidade de cada um (V) e oferta de ensino noturno regular, adequado às condições } \\
\text { do educando (VI) }\end{array}$ \\
\hline
\end{tabular}


Outros pontos da CF tangentes ao acesso mereceriam ser contemplados. Catani (2007, p. 76), por exemplo, menciona alguns dos que afetam a universidade pública federal:

[...] garantiu-se a investidura em cargo ou emprego público mediante a aprovação prévia em concurso público de provas ou de provas e títulos (art. 37, II), aboliram-se as restrições legais que impediam aos servidores públicos de se filiarem a sindicatos (art. 37, VI) e instituiu-se regime jurídico único e planos de carreira homogêneos para os servidores (docentes e funcionários técnico-administrativos) de todas as IFES do país (arts. 24 e 39) (p. 9).

Já na Lei de Diretrizes e Bases de 1996 ressaltam-se os seguintes artigos:

\begin{tabular}{|l|l|}
\hline $\begin{array}{l}\text { artigo } \\
2^{\circ}\end{array}$ & $\begin{array}{l}\text { O ensino deve ser ministrado com base nos princípios: I- igualdade de condições para } \\
\text { o acesso e permanência na escola }\end{array}$ \\
\hline $\begin{array}{l}\text { artigo } \\
44\end{array}$ & $\begin{array}{l}\text { A educação superior abrangerá os seguintes cursos e programas: II- de graduação, } \\
\text { abertos a candidatos que tenham concluído o ensino médio ou equivalente e tenham } \\
\text { sido classificados em processo seletivo }\end{array}$ \\
\hline $\begin{array}{l}\text { artigo } \\
50\end{array}$ & $\begin{array}{l}\text { As instituiçães de educação superior, quando da existência de vagas, abrirão matrícula } \\
\text { nas disciplinas de seus cursos a alunos não regulares que demonstrarem capacidade } \\
\text { de cursá-las com proveito, mediante processo seletivo prévio }\end{array}$ \\
\hline $\begin{array}{l}\text { artigo } \\
51\end{array}$ & $\begin{array}{l}\text { As IES credenciadas como universidade, ao deliberar sobre critérios e normas de } \\
\text { seleção e admissão de estudantes, levarão em conta os efeitos desses critérios } \\
\text { sobre a orientação do ensino médio, articulando-se com os órgãos normativos dos } \\
\text { sistemas de ensino }\end{array}$ \\
\hline
\end{tabular}

Ao tratar do acesso nessas âncoras legais cabe ressaltar os artigos 208 (V) da CF e os artigos 44 e 50 da LDB, antes citados, por reforçarem a seletividade como paradigma. Entende-se que "capacidade de cada um" e "classificação" expressam conteúdos ideológicos associados à atribuição individual de sucesso ou fracasso na vida escolar, tendendo a neutralizar ou a esconder as responsabilidades sociais implicadas na questão, como o papel do Estado perante os bens sociais. Essa questão reflete-se na definição de políticas de acesso, motivo pelo qual adiante se retorna a ela.

O que segue procura mapear planos e programas referentes ao acesso, bem como indicadores da realidade, procurando traçar um quadro das políticas da educação superior.

O documento "PDE - Razões, princípios e programas" (BRASIL, 2007) define objetivos e ações para os níveis e modalidades da educação. No seu in- 
terior, o PDE da Educação Superior elege os seguintes princípios: expansão da oferta de vagas; garantia de qualidade; promoção de inclusão social; ordenação territorial (acesso nas regiões remotas); e desenvolvimento econômico e social. O Programa de Apoio a Planos de Reestruturação e Expansão das Universidades Federais (REUNI) e o Plano Nacional de Assistência Estudantil (PNAES) são indicados para cumprir tais objetivos.

O REUNI, conforme o PDE (BRASIL, 2007, p. 27), refere-se a um "instrumento que permite expandir e defender a universidade pública", além de oferecer "uma expansão democrática do acesso ao ensino superior, o que aumentará expressivamente o contingente de estudantes de camadas sociais de menor renda na universidade pública."

O crescimento de vagas em instituições públicas apresenta-se em sintonia a essa proposta, como pode ser vislumbrado na Tabela 1, de 2006 a 2010, período de fomento dos programas federais, como o Expandir e o REUNI. ${ }^{3}$

Tabela 1 - Evolução do Número de Vagas Oferecidas nos Cursos de Graduação Presenciais, segundo a Categoria Administrativa Pública, 2006 - 2010 - Brasil

\begin{tabular}{lcccccccccc}
\hline \multirow{2}{*}{ Ano } & Total & $\% \Delta$ & \multicolumn{10}{c}{ Pública } \\
\cline { 3 - 11 } & & & Total & $\% \Delta$ & Federal & $\% \Delta$ & Estadual & $\% \Delta$ & Municipal & $\% \Delta$ \\
\hline 2006 & 2.629 .598 & 7,9 & 331.105 & 5,7 & 144.445 & 13,4 & 125.871 & $-2,4$ & 60.789 & 6,5 \\
2007 & 2.823 .942 & 7,4 & 329.260 & $-0,6$ & 155.040 & 7,3 & 113.731 & $-9,6$ & 60.489 & $-\mathbf{0 , 5}$ \\
2008 & 2.985 .137 & 5,7 & 344.038 & 4,5 & 169.502 & 9,3 & 116.285 & 2,2 & 58.251 & $\mathbf{- 3 , 7}$ \\
2009 & 3.164 .679 & 6,0 & 393.882 & 14,5 & 210.236 & 24 & 126.926 & 9,2 & 56.720 & $\mathbf{- 2 , 6}$ \\
2010 & 3.120 .192 & $-1,41$ & 445.337 & 13,2 & 248.534 & 18,2 & 138.318 & 8,9 & 58.485 & 3,1 \\
\hline
\end{tabular}

Fonte: adaptado de INSTITUTO NACIONAL DE ESTUDOS E PESQUISAS EDUCACIONAIS ANÍSIO TEIXEIRA. Censo da educação superior: 2010 - resumo técnico. Brasília: INEP, 2012

Tal panorama mostra uma movimentação na educação superior pública, sobretudo, no setor federal, caracterizada pela maior presença do Estado no financiamento da expansão, segundo um projeto de alterar o quadro de extrema elitização do ensino superior. No entanto, em meio a tal iniciativa, há contradições cruciais, como o insuficiente investimento frente à demanda (a taxa de escolaridade líquida era de 14,4\%, em 2009); o chamado "quase-mercado"

3 O impacto de iniciativas federais no que se refere ao quantitativo de vagas também envolve a criação da Universidade Aberta do Brasil e a expansão da rede federal de educação profissional e tecnológica, ambos em franco desenvolvimento no país. 
(privatização do espaço público); o aligeiramento na formação do estudante (cursos de curta duração, turmas numerosas, expansão sem a necessária cobertura física, de docentes e critérios qualitativos); a precarização do trabalho do docente, entre outros.

Indo adiante, no rastro do significado dos termos acesso/permanência, recorrendo ao documento "Diretrizes REUNI" (BRASIL, 2007), tem-se que:

A ampliação de políticas de inclusão e de assistência estudantil objetiva a igualdade de oportunidades para o estudante que apresenta condições sócio-econômicas desfavoráveis. Esta medida está diretamente associada à inclusão, democratização do acesso e permanência de forma a promover a efetiva igualdade de oportunidades, compreendidas como partes integrantes de um projeto de nação (BRASIL, 2007, p. 6).

O referido documento expressa a:

[...] promoção de inclusão social pela educação, minorando nosso histórico de desperdício de talentos, considerando que dispomos comprovadamente de significativo contingente de jovens competentes e criativos que têm sido sistematicamente excluídos por um filtro de natureza econômica (p. 26).

Para enfrentar essa realidade, ou seja, atender aos candidatos com menores chances de ingresso num contexto excludente, o PDE anuncia o PNAES, regulamentado pela Portaria Normativa MEC n. 39 de 12/12/2007. O programa se apresenta como "estratégia de combate às desigualdades sociais e regionais" com vistas à "ampliação e democratização das condições de acesso e permanência dos jovens", o que se traduz por um conjunto de ações (moradia; alimentação; transporte; assistência a saúde; inclusão digital; cultura; esporte; creche; apoio pedagógico) a serem executadas pelas Instituições Federais de Ensino Superior para atender aos estudantes de graduação selecionados por critérios sócio-econômicos. Segundo esse propósito, o MEC anunciou para 2011 um repasse de 395 milhões às universidades federais com vistas ao acesso de jovens oriundos da rede pública de educação básica ou com renda per capita de até um salário mínimo e meio. Tal valor representa um crescimento de 30\% sobre os gastos com o Programa, comparado a 2010 (MEC..., 2011).

Pela via do setor privado, o governo federal aprovou, em 2005, o Programa Universidade para Todos (PROUNI), cuja finalidade é conceder bolsas de estudo integrais e parciais em cursos de graduação e sequenciais de formação específica 
em instituições privadas de educação superior, mediante isenção de tributos federais, a saber: Imposto de renda das Pessoas Jurídicas (IRPJ); Contribuição Social sobre o Lucro Líquido (CSLL); Contribuição Social para Financiamento da Seguridade Social (CONFINS); e Contribuição para o Programa de Integração Social (PIS). A concessão de bolsas considera o fator sócio-econômico, oferecendo bolsa integral aos que tenham estudado todo o ensino médio em escola pública e comprovem renda familiar mensal per capita que não exceda o valor de 1 (um) salário-mínimo e 1/2(meio; já as bolsas de estudos parciais de $50 \%$ ou de $25 \%$ são concedidas aos que comprovarem renda familiar mensal per capita que não exceda o valor de 3 (três) salários-mínimos. ${ }^{4}$ Por sua vez, a seleção para o programa considera a nota média de corte obtida no Exame Nacional de Ensino Médio (ENEM) e a aprovação em processo seletivo definido pela instituição de ensino. Está prevista, ainda, a reserva de um percentual de bolsas aos afrodescendentes, indígenas e a quem possua deficiência, proporcionalmente ao seu número em cada unidade federativa, com base nos dados do último Censo do IBGE.

No SISPROUNI/MEC não há informação quanto ao número de bolsas PROUNI ofertadas por organização acadêmica. Porém, algumas aproximações podem ser feitas, visto que se sabe que as Faculdades detêm a supremacia numérica no sistema (das 2.378 IES existentes, 2.025 eram Faculdades, em 2010). Considerando que em 2012/1 a oferta de bolsa ocorreu em 1.321 IES privadas, é possível que para as Faculdades direcione-se a maior parcela de bolsas do citado programa. Evidentemente, os dados devem ser relativizados tendo em vista os diferentes anos considerados e a carência de dados. Confirmando-se a suposição, a designação "Universidade para Todos" se mostra um paradoxo.

Em relação aos dados gerais da educação superior no país, a Tabela 2 mostra que, em 2010, as Faculdades concentravam 41,59\% (1.297.537) da oferta de vagas. No entanto, em relação às matrículas, a maior concentração localizava-se nas Universidades, com 51,57\% (2.809.974), o que sugere que as vagas ofertadas pelas instituições não universitárias não estão sendo ocupadas. Os dados do Censo da Educação Superior de 2010 demonstram, ainda, que 55,8\% das vagas no setor privado não eram preenchidas, enquanto no setor público correspondiam a $8 \%$. Por sua vez, entre as organizações acadêmicas, os Centros Universitários apresentavam a maior percentagem de vagas não preenchidas, com 59,9\%, seguidos pelas Faculdades, com 57,6\% (BRASIL, 2010).

4 A propósito, estudo de Carvalho (2011) sobre o ingresso de diferentes extratos sociais mostra que, até 2009 , houve aumento da taxa de escolarização líquida e bruta no segmento de baixa renda, a despeito de continuar a brutal desigualdade entre os extratos. 


\section{Tabela 2 - Demonstrativo da oferta de Vagas e Matrículas nos Cursos de Graduação Presenciais por Organização Acadêmica e Categoria Administrativa - Brasil 2010}

\begin{tabular}{lrrrrrr}
\hline & Universidades & $\begin{array}{c}\text { Centros } \\
\text { Universitários }\end{array}$ & Faculdades & IF e CEFET & \multicolumn{1}{c}{ Total } & \\
\cline { 2 - 8 } Administrativa & $\mathrm{N}$ & $\mathrm{N}$ & $\mathrm{N}$ & $\mathrm{N}$ & $\mathrm{N}$ & $\%$ \\
\hline Vagas & & & & & & \\
Público & 362.295 & 7.700 & 45.531 & 29.811 & 445.337 & 14,27 \\
Privado & 895.362 & 527.487 & 1.252 .006 & - & 2.674 .855 & 85,73 \\
Total & $\mathbf{1 . 2 5 7 . 6 5 7}$ & $\mathbf{5 3 5 . 1 8 7}$ & $\mathbf{1 . 2 9 7 . 5 3 7}$ & $\mathbf{2 9 . 8 1 1}$ & $\mathbf{3 . 1 2 0 . 1 9 2}$ & \\
\hline Matrículas & & & & & & \\
\hline Público & 1.272 .971 & 14.166 & 105.987 & 68.572 & 1.461 .696 & 26,82 \\
Privado & 1.537 .003 & 727.465 & 1.722 .956 & 0 & 3.987 .424 & $\mathbf{7 3 , 1 8}$ \\
Total & $\mathbf{2 . 8 0 9 . 9 7 4}$ & $\mathbf{7 4 1 . 6 3 1}$ & $\mathbf{1 . 8 2 8 . 9 4 3}$ & $\mathbf{6 8 . 5 7 2}$ & $\mathbf{5 . 4 4 9 . 1 2 0}$ & \\
\hline
\end{tabular}

Fonte: adaptado de INSTITUTO NACIONAL DE ESTUDOS E PESQUISAS EDUCACIONAIS ANÍSIO TEIXEIRA. Censo da educação superior: 2010 - resumo técnico. Brasília: INEP, 2012.

Cruzando-se dados, repara-se que onde a oferta de vagas está concentrada (no setor privado) a avaliação de cursos apresenta baixo desempenho. Cabe registrar que os resultados do Exame Nacional de Desempenho de Estudantes (ENADE) $^{5}$, segundo informativo da CONTEE (home page, publicado em 08/08/2008), indicam que, dos 3.237 cursos avaliados em 2007, 1.493 eram públicos e 1.744 privados. Entre os cursos que receberam conceitos 1 e 2 (conceitos baixos), 67,4\% eram oferecidos por instituições privadas; já entre os cursos que obtiveram conceito 5 (conceito alto) na avaliação, 94,4\% eram públicos.

Em relação à taxa de diplomação, mesmo não se tendo suficiente clareza do impacto do fator avaliação de curso sobre a mesma, é possível fazer inferências, comparando-se dados do setor público e do setor privado, de acordo com o que se apresenta na Tabela 3. Ali se percebe que o setor privado apresenta taxas de diplomação inferiores ao do público, exceto nos Centros Universitários, em que a situação se inverte.

5 A avaliação como indicador de qualidade nas políticas públicas requer analises mais aprofundadas, que escapam ao alcance deste texto. Um ponto crítico é o de que a avaliação referente ao ENADE supervaloriza a mensuração. Isso remete a que se concentre no controle e na punição, não raro, implicando na transferência de responsabilidades à gestão institucional ou no conhecido ranqueamento. Assim, entende-se que a avaliação institucional não deve se reduzir a esse exame específico, procurando levar em conta o que o SINAES, na sua origem, previa. Contudo, as sinalizações que os dados emitem não podem ser desconsideradas, sobretudo, se for levada em conta uma série histórica de resultados. 
Tabela 3 - Demonstrativo de Ingressos, Concluintes e Taxa de Diplomação nos Cursos de Graduação Presenciais por Organização Acadêmica e Categoria Administrativa - Brasil

\begin{tabular}{lrrrrrrr}
\hline & \multicolumn{2}{c}{ Universidades } & \multicolumn{2}{c}{ Universitários } & \multicolumn{2}{c}{ Faculdades } & \multicolumn{1}{c}{ CEFET } \\
\cline { 2 - 8 } & Público & Privado & Público & Privado & Público & Privado & Público \\
\hline Ingressos 2005 & 255.560 & 819.236 & 5.066 & 215.845 & 27.505 & 457.865 & 15.419 \\
Concluintes 2008 & 162.091 & 268.563 & 3.591 & 119.062 & 18.034 & 224.935 & 4.042 \\
Taxa Diplomação & $\mathbf{6 3 , 4 3}$ & $\mathbf{3 2 , 7 8}$ & $\mathbf{7 0 , 8 8}$ & $\mathbf{5 5 , 1 6}$ & $\mathbf{6 5 , 5 7}$ & $\mathbf{4 9 , 1 2}$ & $\mathbf{2 6 , 2 1}$ \\
Ingressos 2006 & 249.614 & 432.031 & 4.806 & 232.607 & 25.539 & 486.464 & 17.448 \\
Concluintes 2009 & 163.051 & 263.993 & 2.283 & 135.959 & 17.505 & 239.172 & 4.965 \\
Taxa Diplomação & $\mathbf{6 5 , 3 2}$ & $\mathbf{6 1 , 1 1}$ & $\mathbf{4 7 , 5 0}$ & $\mathbf{5 8 , 4 5}$ & $\mathbf{6 8 , 5 4}$ & $\mathbf{4 9 , 1 6}$ & $\mathbf{2 8 , 4 6}$ \\
Ingressos 2007 & 250.400 & 463.195 & 5.025 & 207.622 & 22.256 & 512.647 & 20.810 \\
Concluintes 2010 & 155.100 & 257.410 & 2.000 & 133.523 & 16.221 & 259.946 & 5.086 \\
Taxa Diplomação & $\mathbf{6 1 , 9 4}$ & $\mathbf{5 5 , 5 7}$ & $\mathbf{3 9 , 8 0}$ & $\mathbf{6 4 , 3 1}$ & $\mathbf{7 2 , 8 8}$ & $\mathbf{5 0 , 7 1}$ & $\mathbf{2 4 , 4 4}$ \\
\hline
\end{tabular}

Fonte: Tabela elaborada pelas autoras a partir dos dados Censo INEP/MEC/ 2005, 2006, 2007, 2008, 2009, 2010

Ao se observar a avaliação de cursos e a taxa de diplomação, há indicação de que a baixa avaliação associa-se à alta desistência. Certamente, os riscos da generalização existem, o que remete à necessidade de estudos mais apurados.

Outro aspecto a ser salientado na discussão sobre o acesso à educação superior refere-se à titulação e à dedicação do corpo docente. Cabe atentar que nas Faculdades privadas, em 2010, do total de seu quadro docente (126.722), $10,7 \%$ eram Doutores e $41,14 \%$ eram Mestres, enquanto nas Universidades esses valores correspondiam a 41,4\% e 33,5\%, respectivamente, com destaque para as Universidades públicas, em que $52,4 \%$ de seu corpo docente possuía o título de Doutor. Tal quadro, indubitavelmente, remete à baixa produção de pesquisa e à inexistência ou escassa constituição da pós-graduação, elementos articulados que repercutem na formação do estudante. Observe-se que dos 1.460 programas de mestrado/doutorado existentes no país em 2010, a maioria absoluta concentrava-se nas Universidades públicas, sobretudo federais.

A luz dos dados e argumentos apresentados considera-se que a Universidade pública é a instituição que favorece a democratização das relações político-acadêmicas e administrativas. No entanto, essa premissa somente será confir- 
mada se houver manutenção institucional pelos fundos públicos, garantindo a autonomia na definição e no desenvolvimento de projetos de pesquisa, ensino e extensão, e, assim, permitindo que a mesma exerça o papel da crítica e de protagonista na construção e reprodução do conhecimento socialmente acumulado pela humanidade. Nisso também está implicada a questão da participação discente/docente nas decisões, um indicador que remete à livre manifestação, mobilização e organização nos espaços institucionais. Nesse sentido, entende-se que a participação política encerra um papel educativo essencial, transcendendo os limites da aula em si, embora sobre ela possa exercer influência.

Avançando na pesquisa documental, retrata-se o Projeto de Lei 8.035/2010, em trâmite no Congresso Nacional, com vistas ao Plano Nacional de Educação (PNE 2011/2020). Em síntese, estão presentes no documento os seguintes aspectos relacionados ao acesso à educação superior: uso do Exame Nacional do Ensino Médio como critério de acesso à educação superior (3.3); elevação da taxa bruta de matrícula na educação superior para $50 \%$ e a taxa líquida para $33 \%$ da população de 18 a 24 anos (12); ampliação e interiorização do acesso, otimizando a capacidade instalada da estrutura física e de recursos humanos das instituições públicas de educação superior (12.1); ampliação de vagas da rede federal via Rede Federal de Educação Profissional, Científica e Tecnológica e Sistema Universidade Aberta (12.2); ampliação de programas de inclusão e assistência estudantil nas instituições públicas visando ao acesso e sucesso acadêmico do egresso de escola pública (12.5); expansão do Financiamento ao Estudante (12.6); ampliação das políticas afirmativas (12.9); e consolidação de processos seletivos nacionais e regionais para acesso à educação superior como forma de superar exames vestibulares individuais.

Cabe um destaque ao não dito: na meta da taxa de matrícula à educação superior o Projeto de Lei omite o termo "público", detendo-se na explicitação da matrícula em geral, o que parece ser emblemático por retirar do debate (e das políticas públicas) a relação público/privado. Em relação ao financiamento da educação, propõe a ampliação progressiva do investimento público em educação até atingir 7\% do PIB, no mínimo, o que está aquém da reivindicação dos movimentos sociais e entidades representativas, que defendem $10 \%$ do PIB, de imediato. Num balanço breve, é notório que o Projeto de Lei centra-se em referendar políticas públicas já em curso.

$\mathrm{Na}$ explanação dos documentos que refletem as políticas de acesso é pertinente destacar o chamado Novo Enem, processo seletivo da educação superior anunciado em 31/03/2009 pelo Ministério da Educação. No documento "Proposta à Associação Nacional dos Dirigentes das Instituições Federais de 
Ensino Superior" (BRASIL, 2009), o MEC defende a "democratização das oportunidades de concorrência às vagas federais de ensino superior" e sinaliza a proposta de um exame centralizado que favoreceria os estudantes que não teriam condições de se deslocar pelo país a fim de prestar exames. Com o novo formato, segundo o discurso oficial, haveria benefícios, como a reestruturação curricular do ensino médio, a democratização do acesso às universidades públicas e a mobilidade acadêmica (CONRADO; LUZ; SILVA, 2011).

A LDB (art. 44), ao instituir o termo "processo seletivo", consagra formas diversificadas de ingresso na educação superior. Com base nisso, o SiSU foi criado, sob o argumento de que possibilitaria a concorrência das vagas nas instituições de ensino superior que aderissem ao sistema, o que evitaria que o estudante se submetesse a um processo de seleção diferente para cada universidade em que pleiteasse uma vaga, se locomovesse para diferentes cidades onde pretendesse prestar o vestibular e pagasse uma taxa de inscrição em cada seleção que participasse.

O sistema caracteriza-se pela possibilidade de sucessivas alterações na definição do curso, desde que a pontuação obtida na prova do ENEM permita, de acordo com a relação candidato/vaga. Nesse aspecto, não é de se desprezar o risco de que a escolha do curso sofra banalização. Sabe-se que o ingresso em universidade federal carrega a crença de "garantia de futuro profissional"; assim, para o candidato, importaria ingressar no curso possível, ou onde os pontos permitam. Nessa linha, a definição do curso, um dos elementos condicionantes da qualidade na formação, parece reduzir-se a uma moeda de troca (a pontuação define a escolha), o que pode induzir a desistências, baixo rendimento e frustrações pessoais e profissionais.

Assim, apesar do discurso de democratização do acesso que acompanha o referido formato seletivo, cabe a ponderação de Oliveira et al (2008, p. 84), segundo a qual não ocorrem mudanças substanciais se as inovações de seleção não alteram o panorama de seletividade social e de escolha elitista que "privilegia os candidatos com maior capital econômico e cultural". Esse ponto, ao que se mostra, permanece intocável no que se refere ao referido formato seletivo.

No desfecho da apresentação dos documentos que ilustram as políticas de acesso à educação superior, o que segue trata de significados que se evidenciam. Avalia-se que o acesso, ao ser qualificado como democratizante ou inclusivo, do ponto de vista dos documentos oficiais, traduz a intenção de ampliar o ingresso e a permanência na educação superior da população com menor poder aquisitivo. Ilustra bem, nesse sentido, a afirmação de Ristoff (2008, p. 45), ex-representante do INEP/MEC: 
Se a palavra de ordem da década passada foi expandir, a desta década precisa ser democratizar. E isto significa criar oportunidades para que os milhares de jovens de classe baixa, pobres, filhos da classe trabalhadora e estudantes das escolas públicas tenham acesso à educação superior. Não basta mais expandir o setor privado [...]; não basta aumentar as vagas no setor público - elas apenas facilitarão o acesso e a transferência dos mais aquinhoados (grifos do autor).

Entretanto, é importante atentar que o "acesso que inclui ou democratiza-se aos carentes" não contraria a seleção com base no mérito individual. Ou seja: tanto os bolsistas do PROUNI como os beneficiados por programas de ação afirmativa nas instituições públicas não escapam aos processos seletivos. Há, pois, nessa equação a possibilidade de ingresso aparentemente favorável aos "excluídos", mas que preserva o princípio da competência ou do mérito individual. Por sua vez, o filtro classificatório também vale para um contingente numeroso de estudantes, os que se submetem à competitiva seleção nas instituições federais e em estaduais renomadas. Portanto, o mérito como princípio motriz perpassa as diferentes políticas educacionais, renovando o sentido de "captar os melhores", que, no reverso, representa a exclusão dos que "sobram". Ao que está indicado, essa é a lógica fundante das políticas da educação superior no trato do ingresso do estudante.

A propósito da questão, por sua repercussão, é oportuno lembrar a Conferência Mundial sobre Educação Superior, realizada em 1998, em Paris. Dedicando-se a discutir o tema "A educação superior no século XXI: visão e ação", a Conferência contou com a representação de duzentos países (dos quais o Brasil) e cerca de quatro mil pessoas dispostas a debater os rumos globais da educação superior, tendo em vista ajustar-se às exigências da chamada "sociedade do conhecimento". Do documento publicado cabe destacar o eixo "igualdade de acesso", em que se extrai a idéia de "[...] admissão baseada no mérito, capacidade, esforços, perseverança e determinação mostradas por aqueles que buscam acesso à educação superior" (UNESCO, 1998, p. 18). Nesse sentido, "[...] em todas as políticas futuras referentes ao acesso à educação superior dê-se preferência a uma aproximação baseada no mérito individual." (p. 19).

De igual forma, não é de se desprezar o sentido atribuído ao acesso conferido na Convenção de Lisboa para o Reconhecimento ${ }^{6}$, como parte das definições

6 A dinâmica de definição de propostas e de encaminhamentos do Processo de Bolonha realizou-se por reuniões periódicas em diversos países europeus; nessa perspectiva, a Reunião de Lisboa aconteceu em 2000 . 
do Processo de Bolonha, visto que estudos indicam a interface da reforma no sistema de educação superior europeu com o brasileiro (SILVA; NOGUEIRA, 2011). Conforme Schettini (2009, p. 284), no documento o termo é utilizado como " $[. .$.$] direito de apresentar a própria candidatura e ser levado em consi-$ deração para a admissão a um curso de estudo de ensino superior”. Em outras palavras, acesso restringe-se ao direito a candidatar-se, a competir.

Assim, tem-se que, se a Conferência Mundial de Educação (1998) enfatiza o acesso como mérito individual, Bolonha o relaciona à seleção competitiva. São visões convergentes na negação do caráter universal das políticas públicas.

Catani e Oliveira $(2002$, p. 78$)$ reiteram que as entidades internacionais apresentam uma defesa insistente do acesso (ou do ingresso) com base no mérito ou na capacidade individual. Tal fundamento, para os autores, significa um reforço da idéia liberal dos dons, talentos e capacidades naturais, ou, em outras palavras, reforço da crença de que tem origem em "dote de nascença ou uma doação divina".

Interessante, nesse sentido, atentar à origem da palavra: mereo, merecer e cracia, poder, governo. Dessa composição, institui-se socialmente a idéia de que o poder é impessoal, próprio de iluminados, independe de condicionamentos externos. O filtro seletivo, seja em que formato se apresente, cumpre o papel de determinar os escolhidos, legitimados pela aura de vencedores, eleitos, especiais. Não por acaso, nisso está associada a idéia de universidade como lugar dos iluminados, da produção do conhecimento de alto nível, do culto ao saber, de definição das divisões epistemológicas, etc.

Conforme se nota, o tema acesso desperta feixes de discussão que envolve, inclusive, as finalidades da educação superior, seja no sentido de entendê-la como santuário sagrado, seletivo e competitivo, ou, no contraponto, como lugar de problematizar, interpretar e construir formas solidárias de intervenção no mundo, e que isso seja compartilhado com os que desejam realizar essa tarefa social por meio da educação superior.

\section{SÍNTESE PROBLEMATIZADORA}

A centralidade do acesso nas políticas educacionais significa avanços na medida em que tem provocado expansão do ingresso e alteração no quadro de desigualdade crônica que marca a história da educação superior brasileira. Não obstante, as medidas para a permanência dos estudantes são ainda limitadas. Além disso, não há indicações de intervenção abrangente ou consistente em relação ao fator qualidade do ensino; ao contrário, determinadas medidas geram 
dúvidas quanto às suas consequências, na perspectiva do acesso contemplado neste texto.

Entende-se, pois, que se trata de "certos avanços" na política de acesso, bem vindos em alguns aspectos, mas passíveis de crítica, considerando a insuficiência e as marcas da precarização implicadas. A base dessa reflexão está no entendimento de acesso que combine, articuladamente, ingresso, permanência e formação qualificada - ponto de vista que contribui para levantar questionamentos nem sempre evidenciados nas ações que configuram a educação superior. $\mathrm{O}$ acesso tende a ser visto e adotado pelas políticas públicas segundo aspectos isolados, a exemplo de considerar que um novo formato seletivo seja responsável pela sua democratização, ou que assim seja em relação a programas de assistência estudantil ou a expansão de vagas públicas. Essa inclinação faz persistir problemas causais e cria uma noção de resolução ilusória, que, afinal, cumpre uma função de acomodação às reformas.

Assim, com a ressalva de que se faz necessário desenvolver pesquisas que apreendam dados empíricos mais refinados, avalia-se que se mostram sinais no sentido de que a democratização do acesso transcorre sem referência ao acesso democrático, no que esse tem de elevado, substancial, abrangente. Por isso, está por se construir a educação como bem social, produzido e acessado pela humanidade, plenamente.

\section{REFERÊNCIAS}

BOBBIO, Norberto. Democracia. In: BOBBIO, Norberto; MATTEUCCI, Nicola; PASQUINO, Gianfranco. Dicionário de política. Brasília: Ed. UnB, 2004. (Verbete).

BRASIL. Ministério da Educação. Sinopse da Educação Superior 2010. Disponível em: $<$ http://portal.inep.gov.br/superior-censosuperior-sinopse>. Acesso: 10 dez. 2010.

. Proposta à Associação Nacional dos Dirigentes das Instituições

Federais de Ensino Superior 2009. Disponível em: <http://portal.mec.gov. br/index.php?Itemid=310+enen.br $>$. Acesso: $10 \mathrm{dez} .2010$.

. Sinopse da Educação Superior 2007. Disponível em: <http:// portal.inep.gov.br/superior-censosuperior-sinopse>. Acesso: $10 \mathrm{dez} .2010$. 
CAMPOS, Benedicto. Introdução à filosofia marxista. São Paulo: AlfaÔmega, 1988.

CARVALHO, Cristina Helena Almeida de. Uma análise crítica do financiamento do PROUNI: instrumento de estímulo à iniciativa privada e/ ou democratização do acesso à educação superior? In: REUNIÃO ANUAL DA ANPED, 34., 2011. Natal, RN. Resumos..., Natal: ANPEd, 2011.

CATANI, A. M. Pierre Bourdieu: diálogos - compreendendo os fundamentos ocultos da dominação. Educação, São Paulo, v. 5, p. 74-83, 2007.

CATANI, Afrânio Mendes; OLIVEIRA, João Ferreira de. Educação superior no Brasil. Reestruturação e metamorfose das universidades públicas. Petrópolis: Vozes, 2002.

CHEPTULIN, Alexandre. A dialética materialista. Categorias e leis da dialética. São Paulo: Alfa Ômega, 2004.

COUTINHO, Carlos Nelson. A democracia na batalha das ideias e nas lutas políticas do Brasil de hoje. In: FÁVERO, Osmar; SEMERARO, Giovanni.

Democracia e construção do público no pensamento educacional brasileiro. Petrópolis: Vozes, 2002.

CONRADO, Nayara Dias de Menezes; LUZ, Jackeline Nascimento Noronha; SILVA, Maria das Graças Martins da. Acesso à educação superior pelo SiSU no curso de Pedagogia da UFMT: evidências iniciais. In: SILVA, Maria das Graças Martins da (Org.). Políticas educacionais: faces e interfaces da democratização. Cuiabá: Ed. UFMT, 2011.

ELEY, Georff. Forjando a democracia. A história da esquerda na Europa, 1850-2000. São Paulo: Fundação Perseu Abramo, 2002.

ENGUITA, Mariano Fernandes. O discurso da qualidade e a qualidade do discurso. In: GENTILI, Pablo; SILVA, Tomaz Tadeu da (Orgs.).

Neoliberalismo, qualidade total e educação. Petrópolis: Vozes, 1996. p. 95-110.

INSTITUTO NACIONAL DE ESTUDOS E PESQUISAS EDUCACIONAIS ANÍSIO TEIXEIRA. Censo da educação superior: 2010 - resumo técnico. Brasília: INEP, 2012.

KOSIK, Karel. Dialética do concreto. Rio de Janeiro: Paz e Terra, 2002. 
MARX, Karl. Manuscritos econômico-filosóficos. São Paulo: Martin Claret, 2005.

MEC gasta 140\% mais com ajuda estudantil. Jornal da Ciência, 4277 de 10 jul. 2011. Disponível em: <http://www.jornaldaciencia.org.br/Detalhe. jsp?id=77325>. Acesso em: 22 jul. 2011.

MINAYO, Maria Cecília de Souza. O desafio do conhecimento. Pesquisa qualitativa em saúde. São Paulo; Rio de Janeiro: Hucitec; Abrasco, 2000.

OLIVEIRA, João Ferreira de; CATANI, Afrânio Mendes; HEY, Ana Paula; AZEVEDO, Mario Luiz Neves de. Democratização do acesso e inclusão na educação superior no Brasil. In: BITTAR, Mariluce; OLIVEIRA, João Ferreira de; MOROSINI, Marília (Org.). Educação Superior no Brasil: 10 anos pós-LDB. Brasília: INEP, 2008. p. 71-88.

RISTOFF, Dilvo. Educação superior no Brasil - 10 anos pós-LDB - da expansão à democratização. In: BITTAR, Mariluce; OLIVEIRA, João Ferreira; MOROSINI, Marília. Educação superior no Brasil: 10 anos pós LDB. Brasília: INEP, 2008. p. 39-50.

SCHETTINI, Bruno. Bolonha versus Lisboa: contradições e ambiguidades na Itália e na Europa. Revista Educação Pública, Cuiabá, v. 18, n. 37, p. 241-416, maio/ago. 2009.

SILVA, Maria das Graças Martins; NOGUEIRA, Patrícia Simone. Expansão na educação superior e a política de democratização: avanços e contradições. In: SILVA, Maria das Graças Martins (Org.). Políticas educacionais: faces e interfaces da democratização. Cuiabá: Ed. UFMT, 2011.

SILVA, Maria das Graças Martins; VELOSO, Tereza Christina Mertens Aguiar. Acesso na educação superior: significados e tendências em curso. Série Estudos, Campo Grande, n. 30, p. 10-25, jul./dez. 2010.

SILVA, Antonia Almeida. Democracia e democratização da educação: primeiras aproximações a partir da teoria do valor. In: PARO, Vitor Henrique. A teoria do valor em Marx e a educação. São Paulo: Cortez, 2006.

SILVA FILHO, Roberto Leal Lobo; MONTEJUNAS, Paulo Roberto; HIPÓLITO, Oscar; LOBO, Maria Beatriz de Carvalho. Melo. Cadernos de Pesquisa, São Paulo, v. 37, n. 132, p. 1-18, set./dez. 2007. 
TRIVIÑOS, Augusto. Dialética e pesquisa em ciências sociais. In: MOLINA NETO, Vicente; TRIVIÑOS, Augusto (Orgs.). A pesquisa qualitativa na educação física. Porto Alegre: Sulina, 2004.

UNESCO. Declaração mundial sobre educação superior. Declaração mundial sobre educação superior no século XXI: visão e ação. Marco referencial de ação prioritário para a mudança e o desenvolvimento da educação superior. Piracicaba: Ed. UNIMED, 1998.

VELOSO, Tereza Christina Mertens Aguiar. A evasão nos cursos de graduação da Universidade Federal de Mato Grosso, campus Cuiabá 1985 a 1995/2. Um processo de exclusão. 123 f. 2000. Dissertação (Mestrado em Educação)-Instituto de Educação, Universidade Federal de Mato Grosso, Cuiabá, 2000.

WOOD, Ellen Meiksins. Democracia contra o capitalismo. A renovação do materialismo histórico. Perdizes: Boitempo, 2003. 